Rev Inv Vet Perú 1999; 10(2):33-38

\title{
SEROPREVALENCIA DEL Mycobacterium paratuberculosis EN BOVINOS LECHEROS DEL VALLE DE LIMA
}

\author{
Alfredo Benito Q. ${ }^{1}$ y Hermelinda Rivera G. ${ }^{2}$
}

\section{Abstract}

This study reports the seroprevalence of Mycobacterium paratuberculosis, the causative agent of Johne's disease, in Peruvian dairy herds. ELISA tests (HerdCheck, IDEXX, USA) were performed on 346 serum samples collected from 18 herds in the Lima valley during 1997. Antibodies against M. paratuberculosis were found in 13.3\% (46/346) of the cows and half $(9 / 18)$ of the herds tested. The incidence of reactors in the infected herds $(16.1 \%=46 / 286)$ varied between 2.9 to $46.2 \%$. ELISA optical density values ranged from 0.30 to 0.69 in $78.2 \%$ (36/46) and 0.7 to $>2.0$ in $21.7 \%$ (10/46) of the positive serum samples, confirming the presence of Johne's disease in dairy herds from the Lima valley.

Key words: Dairy cattle, Mycobacterium paratuberculosis, Johne's disease, antibodies, ELISA.

\section{Resumen}

Con el objeto de determinar la seroprevalencia de Mycobacterium paratuberculosis, agente causal de la enfermedad de Johne, en bovinos lecheros del Valle de Lima se estudiaron 346 muestras de sueros bovinos procedentes de 18 hatos lecheros del Valle de Lima, colectados durante 1997. La detección de los anticuerpos contra el $M$. paratuberculosis fue realizada mediante la prueba de ELISA (HerdCheck, IDEXX, USA). El 13,3\% (46/346) de las muestras presentaron anticuerpos contra $M$. paratuberculosis. E1 50\% (9/18) de los establos muestreados estuvieron infectados. Del total de animales de los establos infecta$\operatorname{dos}(n=286), 42(16,1 \%)$ animales tuvieron anticuerpos contra $M$. paratuberculosis, pero los porcentajes de animales seroreactores en estos hatos fluctuaron entre 2,9 a 46,2\%. El $78,2 \%(36 / 46)$ de las muestras positivas tuvieron densidades ópticas (DO) entre 0,30 a 0,69 mientras que el $21,7 \%(10 / 46)$ tuvieron entre 0,70 a $>$ a 2,0 . Los resultados del presente estudio corroboran la presencia de la paratuberculosis en el país y evidencia su amplia distribución en los establos lecheros del Valle de Lima.

Palabras Clave: Bovinos, Mycobacterium paratuberculosis, enfermedad de Johne anticuerpos, ELISA.

\section{Introtuccion}

La paratuberculosis o enfermedad de Johne es un proceso infeccioso crónico que

\author{
1 Práctica privada \\ 2 Laboratorio de Microbiología - FMV - \\ UNMSM.d170029@unmsm.edu.pe
}

afecta a los rumiantes domésticos y silvestres. La lesión se localiza principalmente en el intestino delgado, en la parte distal del ileon, produciendo una enteritis granulomatosa y como consecuencia los animales afectados presentan diarrea crónica incurable, emaciación, reducción en la producción de leche (Chiodini, 1992; Thoen y Haagsma, 1996). 
La enfermedad tiene gran impacto económico debido al descenso de la productividad, susceptibilidad incrementada a otras infecciones como la mastitis y eliminación temprana de los animales afectados. (Van Shaik et al., 1996; Hutchinson, 1996).

El agente causal es el $M$. paratuberculosis, un pequeño bacilo aerobio, Gram positivo, ácido resistente y un parásito intracelular obligado, especialmente en macrófagos (Collins,1996; Jark et al., 1997). El $M$. paratuberculosis es genéticamente similar pero fenotíticamente diferente al $M$. avium siendo uno de estas diferencias su mayor virulencia para los mamíferos. Recientemente el $M$. paratuberculosis ha sido propuesto ser denominado $M$. avium subespecie paratuberculosis (Collins, 1997).

El $M$. paratuberculosis es eliminado a través de las heces y la leche del animal infectado, sobre todo en la etapa avanzada de la enfermedad (Thoen y Haagsma, 1996); por lo que el agua y alimentos como la leche que son contaminados con heces de los animales infectados constituye medios de transmisión de esta enfermedad (OIE Manual, 1996). Luego de la ingestión, la bacteria se localiza en el intestino delgado (placas de peyer), nódulos linfáticos y tonsilas en donde es fagocitada por los macrófagos pero no es destruida persistiendo dentro del macrófago y evadiendo, de este modo, la respuesta inmune por daño en la función de este importante mecanismo de defensa del animal (Kreeger, 1991).

La enfermedad de Jonhe está siendo considerada como una enfermedad emergente a pesar de su reconocimiento desde hace más de un siglo, debido al frecuente aislamiento de $M$. paratuberculosis de pacientes humanos con la enfermedad de Crohn, un proceso clínico y anatomopatológicamente similar a la enfermedad de Johne; aunque los estudios realizados a la fecha no son concluyentes para afirmar que la enfermedad de Johne o paratuberculosis es una zoonosis (Collins, 1997).
En el Perú, el primer reporte de paratuberculosis se realizó hace 45 años (Ramos et al., 1953), desde entonces no hubo información sobre esta enfermedad hasta el reciente reporte en un animal a través de exámenes histopatológicos por Morales y Araujo (1996) y serológicos en un hato lechero del Valle de Lima (Rivera, 1997, datos no publicados). Por lo que el objetivo de este estudio fue determinar la seroprevalencia de $M$. paratuberculosis en bovinos lecheros del Valle de Lima, mediante la prueba de ELISA y conocer mejor la epidemiología de la enfermedad en el país.

\section{Materinles y Metodos}

Se seleccionaron muestras de sueros del banco de sueros de bovinos del Laboratorio de Virologfa de la Facultad de Medicina Veterinaria de la Universidad Nacional Mayor de San Marcos obtenido durante el año de 1997. Las muestras fueron escogidas de animales de 18 hatos lecheros del Valle de Lima. El tamaño muestral $(n=217)$ fue obtenido tomándose como referencia una prevalencia de $17 \%$ obtenida en un hato lechero del valle de Lima (Rivera, 1997, datos no publicados); y según la fórmula de muestreo simple al azar, con un nivel de confianza del 95\%. (Thrusfield, 1991).

Los anticuerpos fueron detectados mediante la prueba de ELISA obtenido comercialmente (IDEXX, USA) y de acuerdo al manual proporcionado por la compañía.

La densidad óptica (DO) de las muestras analizadas y los sueros controles, fueron corregidos de acuerdo a la siguiente fórmula: DO corregida $=$ DO muestra/control positivo-DO control negativo.

La prueba fue válida siempre que la DO del suero control positivo fuera mayor a 0.8 y la DO del suero control negativo menor a 0.2 , tal como indica el manual. Una muestra fue considerada positiva cuando su DO fue igual o mayor que 0.3 . Una muestra 
fue considerada negativa cuando su DO fue menor que 0.2. Una muestra fue considerada dudosa cuando su DO estuvo entre 0.2 y 0.3 ; las mismas que fueron reevaluadas.

La seroprevalencia relativa o aparente de $M$. paratuberculosis en bovinos lecheros del Valle de Lima fue determinada mediante la fórmula de Thrusfield (1991) y la seroprevalencia corregida fue realizada usando una sensibilidad (S) de $46 \%$ y una especificidad (E) de $99 \%$ reportada para la prueba de ELISA. (Collins y Sockett, 1993; Collins, 1996)

Prevalencia corregida:

$$
\frac{\text { Prevalencia }+E-1}{S+E-1}
$$

\section{Rasulados}

El 13,3\% (46/346) de las muestras de sueros estudiados tuvieron anticuerpos contra $M$. paratuberculosis mediante la prueba de ELISA (prevalencia relativa). La prevalencia corregida indicó que el $27,3 \%$ de estos sueros tuvieron anticuerpos contra el $M$. paratuberculosis.

El 50\% (9/18) de los hatos muestreados estuvieron infectados. Del to- tal de muestras de los 9 establos infectados, el 16,1\% (46/286) presentó anticuerpos contra $M$. paratuberculosis. E1 porcentaje de seroreactores en estos hatos tuvo un rango de 2,9 a 46,2\% (Cuadro 1). En la Figura 1 se muestran las densidades ópticas corregidas (DOc) del total de muestras evaluadas y en la Figura 2, las DOc de todas las muestras positivas que variaron de $0,30 \mathrm{a}>\mathrm{a} 2,00$.

\section{Discustion}

Actualmente la enfermedad de Johne esta siendo de interés para la comunidad científica por su posible implicancia en la salud pública, en este sentido algunos países como Estados Unidos y de la Comunidad Europea están realizando esfuerzos para el control de la enfermedad. La escasa información sobre la enfermedad en nuestro medio y la disponibilidad de una prueba de ELISA para su diagnóstico motivaron la realización del presente estudio en bovinos lecheros procedentes del Valle de Lima.

El 13,3\% (46/346) de las muestras estudiadas presentaron anticuerpos contra $M$. paratuberculosis, confirmando la presencia de la infección en bovinos lecheros del Valle de Lima. La prueba de ELISA utilizada en el presente estudio es actualmenta la herramien-

Cuadro 1. Distribución de las muestras positivas en los establos reactores a Mycobacterium paratuberculosis en bovinos lecheros del Valle de Lima mediante la prueba de ELISA

\begin{tabular}{cccc}
\hline \multirow{2}{*}{ Establo } & \multirow{2}{*}{ Número de sueros } & \multicolumn{2}{c}{ Sueros positivos } \\
\cline { 3 - 4 } & & & $\mathbf{N}^{\circ}$ \\
03 & 6 & 1 & 16,7 \\
05 & 34 & 1 & 2,9 \\
06 & 8 & 1 & 12,5 \\
08 & 40 & 2 & 5,0 \\
09 & 13 & 6 & 46,2 \\
10 & 41 & 6 & 14,6 \\
13 & 78 & 15 & 19,2 \\
15 & 10 & 2 & 20,0 \\
18 & 56 & 12 & 21,4 \\
\hline Total & 286 & 46 & 16,1 \\
\hline
\end{tabular}




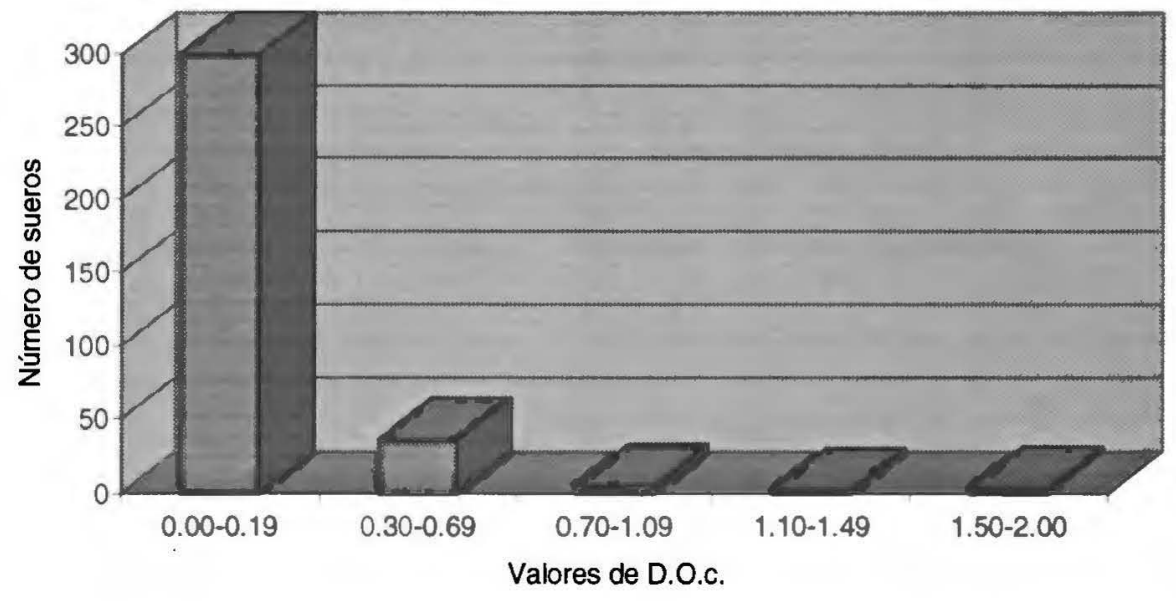

Figura. 1. Densidades ópticas corregidas (DOc) de los sueron evaluados para el estudio de la seroprevalencia de Mycobacterium paratuberculosis en bovinos lecheros del Valle de Lima $(n=346)$.

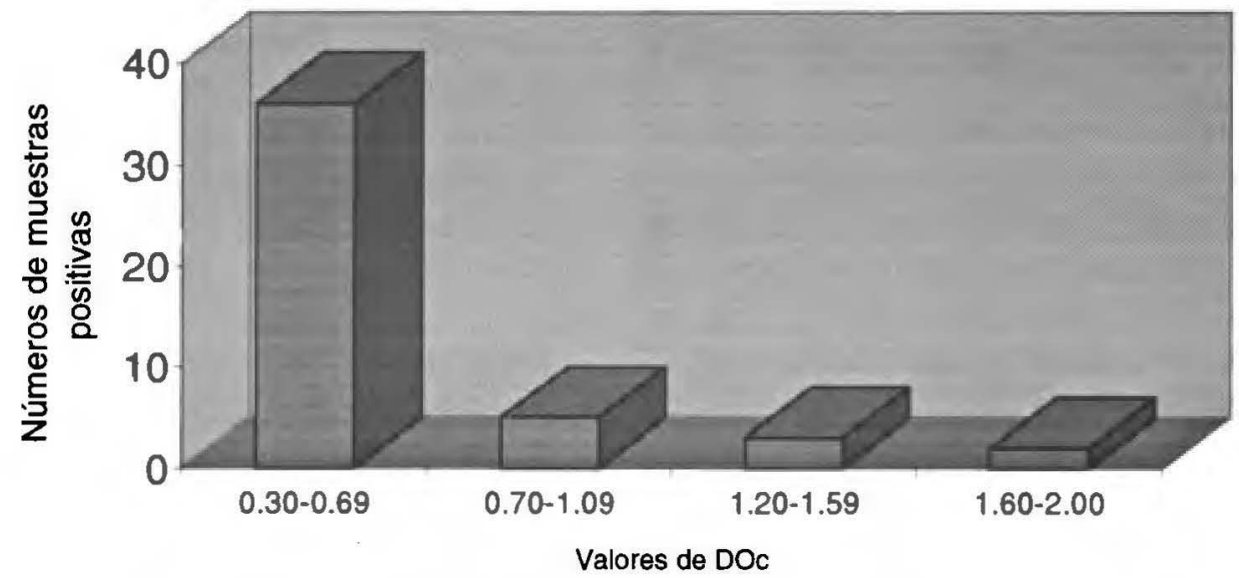

Figura 2. Densidades ópticas corregidas (DOc) de las muestras positivas a Mycobacterium paratuberculosis en bovinos lecheros del Valle de Lima $(n=46)$.

ta más común para realizar estudios epidemiológicos sobre la enfermedad de Johne, pero debido a su baja sensibilidad (46\%) se recomienda realizar una corrección de la prevalencia relativa o aparente (Collins, 1996). Esta corrección determinó que la real prevalencia de la bacteria es de $27,3 \%$.

El 50\% (9/18) de los establos de donde procedieron los sueros estuvieron infectados, debido a la falta de control y al hecho de que la enfermedad no constituye una barrera sanitaria para la importación de bovinos. Estos factores propiciarian la difusión de la infección en los hatos de la cuenca lechera de Lima y posiblemente en otras cuencas como Arequipa y Cajamarca. En Estados Unidos Thorne y Hardin (1997), empleando la prueba de ELISA, reportaron que $74 \%$ y $40 \%$ de los hatos lecheros y de carne respectivamente, fueron reactores a $M$. paratuberculosis; este mayor porcentaje en los hatos lecheros pro- 
bablemente se deba al confinamiento de los animales durante el inviemo y por tanto a un mayor riesgo de contagio.

De los nueve establos infectados, el $16,1 \%(46 / 286)$ de los animales fueron reactores (Cuadro 1). La prevalencia de la bacteria en animales de estos hatos variaron desde 2,9 a $46,2 \%$. Esta variabilidad en la prevalencia posiblemente se deba a los diferentes sistemas de manejo, etapa de la infección durante la toma de muestra, así como, tamaño de la población de animales en los hatos. La benignidad de nuestro clima y la baja densidad de población bovina en relación a los países ganaderos como USA pueden ser algunos factores que contribuya al mantenimiento del nivel de infección sin alcanzar prevalencias superiores a lo reportado en otros países.

El 78,2\% (36/46) de las muestras positivas tuvieron DOc entre 0,30 a 0,69 . La literatura indica que animales en las etapas iniciales de la enfermedad muestran rangos de DOc no mayores a 1, ya que los niveles de anticuerpos se incrementan a medida que la enfermedad progresa (Collins, 1996). Este elevado porcentaje de animales con infecciones supuestamente en etapas iniciales podría sugerir una reciente introducción de la infección al hato a través de animales infectados de procedencia nacional o importados sin control sanitario, ya que esta enfermedad no es considerada restrictiva para las importaciones de bovinos u ovinos al país.

El 21,7\% (10/46) de las muestras con DOc entre 0,7 a $>2,0$ (Fig.1 y 2), podrían evidenciar animales en etapas avanzadas de la enfermedad, ya que DOc superiores a 1.0 son correlacionadas con el inicio de la enfermedad en su forma clínica (Collins, 1996). De acuerdo a este concepto, aproximadamente 10 de los animales muestreados (Fig. 2) estaban con signos clínicos caracterizados principalmente por adelgazamiento progresivo y/o diarreas y podrían estar siendo confundidas con otras patologías como diarrea viral bovina, intoxicación o tuberculo- sis y enviadas al matadero sin un diagnóstico definitivo. Whitlock y Buergelt (1996) indicaron que un animal nacido en el hato y que hace la forma clínica de la enfermedad, puede infectar a un mínimo de 25 animales.

Diversos estudios han demostrado que la paratuberculosis bovina causa pérdidas económicas a la industria lechera (Hutchinson, 1996). Muchos estudios han demostrado que vacas sin signos clínicos pero positivas a $M$. paratuberculosis son eliminadas del hato mayormente por mastitis o infertilidad. Merkal et al., (1975) reportaron que en un hato de 900 vacas se eliminaron $23 \%$ de vacas infectadas subclínicamente con M. paratuberculosis debido a mastitis muy superior al $3.6 \%$ de vacas eliminadas igualmente por mastitis pero negativas a $M$. paratuberculosis. Asimismo, se reporta que vacas con infección subclínica son más susceptibles a otras infecciones y que disminuyen su producción lechera entre 5 a $15 \%$ (Hutchinson, 1996). La susceptibilidad a otras infecciones como la mastitis podría deberse a la falla de actividad fagocítica de los macrófagos.

En nuestro medio ciertos animales de hatos negativos a la tuberculosis reaccionan positivamente ante la aplicación de la tuberculina con el consecuente beneficio del animal ante sospecha de presentar infección por $M$. tuberculosis, pero a la inspección de las vísceras no presentan lesiones tuberculósicas (D. Untiveros, comunicación personal). Estos casos podrían tratarse de reacciones cruzadas debido a infecciones subclínicas con $M$. paratuberculosis (Chiodini et al., 1984) representando pérdidas para el ganadero.

La presencia de la infección en los animales lecheros del Valle de Lima debe interesar a las autoridades sanitarias y ganaderos en general para tomar medidas básicas de control y al mismo tiempo continuar con los estudios de prevalencia en las principales cuencas lecheras del país como Cajamarca, Arequipa y valles interandinos. 
Por otro lado, estudios de prevalencia de $M$ paratuberculosis en ovinos de otros países indican rangos entre 29 a $60 \%$ (Benazzi et al., 1996), por lo que debe iniciarse similares estudios en los ovinos por constituir estos animales uno de los pilares de la economía pecuaria del país.

\section{Literatura Citha}

1. Benazzi, S., M. El Hamidi y Schliesser. 1996. Paratuberculosis in sheep flocks in Morocco: a serological, microscopical and culture survey. Zentralbl Veterinarmed, 43(4): 213-219.

2. Collins, M.T. 1997. Mycobacterium paratuberculosis: A potential food-borne pathogen. J Dairy Sci. 80:3445-3448.

3. Collins, M.T. 1996. Diagnosis of paratuberculosis. Vet Clin North Am Food Anim Pract.12(2): 357-381.

4. Collins, M.T y D.C. Sockett. 1993. Accuracy and economics of the USDAlicensed enzyme-linked immunosorbent assay for bovine paratuberculosis. J Am Vet Med Assoc. 203:1456-1463.

5. Chiodini, R.J., H.J. Van Kruinigen y R.S. Merkal. 1984. Ruminant paruberculosis (Johne's disease). The Cornell Veterinarian. 74(3): 218-262.

6. Chiodini, R.J. 1992. Historical overview and current approaches in determining a Mycobacterial etiology of Crohn's disease. In: Mulder CJJ, Tytgat GNJ, eds . Is Crohn's disease a mycobacterial disease, Kluwer Academic Publishers, Dordretch. p 1-15.

7. Hutchinson, L.J. 1996. Economic impact of paratuberculosis. Vet Clin North Am Food Anim Pract. 12(2): 373381.

8. Jark U., I. Ringena, G-F Ggerlach, B. Franz y M. Beyerbach. 1997. Development of an ELISA technique for serodiagnosis of bovine paratuberculosis. Vet Microbiol. 51:189-198.

9. Kreeger, J.M. 1991. Ruminant paratuberculosis a century of progress and frustration. J Vet Diagn Invest. 3:373383.

10. Merkal, R.S., A.B. Larse y G.D. Booth. 1975. Analysis of the efects of inapparent bovine paratuberculosis. Am J Vet Res. 36: 837

11. Morales, C. y A. Araujo. 1995. Un caso de paratuberculosis bovina. Resumenes del XVIII Reunión Científica Anual. Asociación Peruana de Producción Animal. Lambayeque, Perú.

12. OIE. 1996. Manual of standards for diagnostic tests and vaccines: Paratuberculosis (Johne's disease). 3ed. 218-223.

13. Ramos, S.T., G.E. Gonzales y A. Castillo. 1953. La paratuberculosis bovina (Enfermedad de Johne o enterítis paratuberculosa) nueva enfermedad hallada en el ganado lechero en el Perú. Boletín No.1 FMV. UNMSM.

14. Thoen, C.O. y J. Haagsma. 1996. Molecular techniques in the diagnosis and control of paratuberculosis in cattle. J Am Vet Med Assoc. 209(4):734-737.

15. Thorne, J.G. y L.E. Hardin. 1997. Estimated prevalence of paratuberculosis in Missouri, USA cattle. Prev Vet Med: 31(1-2): 51-57.

16. Thrusfield, M. 1991. Epidemiología Veterinaria. Edit Acribia. p. 191-200. Zaragoza-España.

17. Van Shaik, G., CHJ Kalis y G. Benedictus. 1996. Cost-benefit analysis of vaccination against paratuberculosis in dairy cattle. Vet Rec: 139:624-626.

18. Whitlock, R.H. y C. Buergelt. 1996. Preclinical and clinical manifestation of paratuberculosis. Vet Clin North Am Food Anim Pract. 12(2): 345-356. 